\title{
Chapter 9 \\ Reimagining Housing: Affordability Crisis and Its Role in Disaster Resilience and Recovery
}

\author{
Andreanecia M. Morris and Lucas Diaz
}

\subsection{Introduction}

From a housing perspective, the New Orleans levee failures brought about by Hurricane Katrina and the weakness of the levees can be perceived as a boon and a catastrophe, simultaneously. While it is well documented that the flooding devastation after the storm destroyed a significant portion of New Orleans homes (Pistrika and Jonkman 2010), the same devastation also created new opportunities for a potential real estate renaissance. Unfortunately, with opportunities in real estate development have come the risks of continued status quo in housing inequalities, rearticulated through similar historically entrenched patterns and practices (Germany 2007), ensnaring policymakers and decision-makers at all levels of governance in a familiar game.

For residents and developers in positions to benefit, the post-Katrina New Orleans housing environment has been a boon that has brought new attention and renewed energy to the real estate market (Williams 2018). Some of the factors that have contributed to increased real estate market prices over the past 12 years include Katrina-generated citywide increases in federally funded investments for infrastructure (from roads to local parks and school buildings), coinciding with increased interest in New Orleans after the storm as a retirement and leisure destination for the wealthy, and an affordable place for newcomer entrepreneurs and millennials. These Katrina outcomes benefitted well-positioned real estate owners up to the most recent market slowdown (Thompson 2018). This renewed sense of energy in the area, coupled with a strategically inadequate distribution of tax

\author{
A. M. Morris $(\triangle)$ \\ Housing NOLA/Greater New Orleans Housing Alliance, New Orleans, LA, USA \\ e-mail: amorris@housingnola.org \\ L. Diaz \\ ABD Department of Sociology, Tulane University, New Orleans, LA, USA \\ e-mail: ldiaz5@tulane.edu


incentives doled out to new development projects, also helped create sorely needed new housing stock in the city (Gotham 2015).

Unfortunately, this uptick in development activity and real estate market price growth has done little to alleviate New Orleans' need for housing that is affordable to the city's local workforce. Instead, a housing affordability shortage, created largely by the floodwaters that flowed through the levee breaches, continued to grow without adequate attention from decision-makers, advancing into the crisis the city now faces. In our estimation, the resulting influx of new, wealthy residents, the growth of luxury downtown living units, and the growth of speculative real estate development within popular or trendy neighborhoods have not only addressed the city's growing housing affordability crisis, these factors have exacerbated it, aided in no small part by local and state legislators and housing policy officials who have continued to misunderstand or misdiagnose the reach and impact of this issue. The resulting lack of coordinated, focused attention on the City of New Orleans' growing housing affordability issue at decision-making tables, we argue, poses a risk to the city's ability to develop the essential resilience needed for the type of exceptional recovery required if the city is to keep future disasters from becoming catastrophes.

This chapter provides a praxis-oriented interdisciplinary exploration of how post-Katrina's housing boom has contributed to a growing housing affordability crisis and how advocates and service providers have tackled the challenges and opportunities to provide affordable, safe housing for the local workforce. After a brief review of theoretical literature supporting data, analysis, and interpretation, we provide a snapshot of the elements constituting the housing crisis and then explore how the creation and efforts of the Greater New Orleans Housing Alliance (GNOHA) have led to the growing power of this group to inform and influence housing decision-making in the city. We provide a set of recommendations for groups and localities interested in addressing housing affordability issues, as well as recommendations for further interdisciplinary research, and conclude that ensuring housing affordability for low- to moderate-income families helps build the essential resilience families need to face future disasters.

\subsection{From Theory to Praxis}

This chapter relies on a combination of sociological and political science theories that enable the authors to locate their interpretations within a well-established tradition of disaster resilience and recovery and urban and social movement scholarship. Additionally, we rely on our own praxis as social justice advocates, as well as the praxis of others in power-building work, to provide both data and interpretation, making use of qualitative methodologies in the social sciences.

We first frame our discussion through a disaster resilience lens, using concepts that focus on human-oriented abilities to rebound well from disasters (McNicoll 1996; Tierney 1999; Laska 2012). In particular, we work from Laska's conceptualization of essential resilience as a necessary component of exceptional 
recovery (2012), which we utilize to connect the role housing affordability plays in low- to moderate-income families' abilities to build the type of resilience needed to help mitigate exposure to future disasters. Essential resilience here corresponds to families' abilities to rebound well from future disasters, which we posit is directly related to housing affordability.

Relying on concepts from the "urban growth machine" theory, we assume the role of economic growth and its corresponding logics of a market-centric approach to urban social problems and policies (Molotch 1976; Molotch and Logan 1983). According to Molotch and Logan, the potential negative consequences of a given economic agenda in an urban setting become secondary, or may not be considered at all, in decisions focused on ensuring economic growth (1983). Economic growth logic influences key stakeholders and power players in an urban setting in such a way as to cause them to advance business elites' economic interests at the expense of, or without adequately weighing, potential or actual negative social impacts on vulnerable populations (1983). As Tierney points out, urban growth logics points toward local power relations focused on market-oriented approaches, which apply in disaster planning and response, further exacerbating historical socioeconomic inequities when left unchecked (Tierney 2010). This understanding helps us recognize the role of power dynamics in exploring how housing-related policy and program decisions play out in a given urban setting, which leads us to further consider the roles of different players within a given field and how they operate within that field (Fligstein and McAdam 2012).

Fligstein and McAdam advance decades of social movement theories to arrive at a model that accounts for individual (micro) and regional/national (macro) factors interacting with each other in a given field for the purposes of advancing social, political, economic, or even cultural agendas (2012). The power dynamics, political interactions, and efforts undertaken to advance any group's agenda can be better explained and understood when connecting individual and group actions to the environment in which these actions take place (the field). Finally, in our exploration of GNOHA's growth, actions, and evolution, we highlight implications and potential steps for others to consider, which rely on our application of concepts from regime politics theory (Stone 1989, 1998, 2006). According to Stone, regimes in urban spaces succeed in advancing agendas when cooperation across group interests coalesces into actionable items that the majority of power brokers (across civic, business, and government) agree to support $(1989,1998,2006)$.

Finally, we apply reflexive (Pensoneau-Conway and Toyosaki 2011) and institutional ethnography (Campbell 1998) in order to account for and enable the lived field expertise of the authors as data for analysis and interpretation. This methodology allows us to locate our praxis expertise as interpretable data, both as it relates to our experiences as individuals working in the housing universe and as it relates to our experiences within the institutions through which the work is conducted, as well as the field in which it takes place.

Our approach to describing this case and its analysis provided in this chapter is limited in its scope, requiring that we make explicit some of the most salient of these. First, the interpretations in this chapter are not generalizable to a broader 
population. Our insight is limited to the specific field of housing in New Orleans, and any lessons our interpretations may provide will be mostly of use to practitioners rather than to scholars. Second, this chapter's aim is to promote further discussion and lines of inquiry rather than to fully test a hypothesis. Thus, it is intended to provide potential insights for practitioners rather than theoretically connect causal factors to effects. As such, we encourage both praxis and academic readers to explore this chapter with an eye toward strengthening and advancing both future praxis and scholarly work related to housing affordability and its relationship to disaster resilience. It is a critical topic, we believe, after a disaster and especially in a catastrophe such as was Hurricane Katrina.

\subsection{A Housing Affordability Crisis in the Shadow of Katrina}

New Orleans is renowned for its culture and tourist attractions. More important to New Orleans locally are its neighborhoods and people. Residents perceive themselves through the lens of their neighborhoods first. To retain what we believe is our most precious asset, our residents, efforts must be made to ensure that everyone has an affordable place to call home. From first responders to hospitality employees, teachers, child care workers, and culture bearers, all New Orleanians deserve access to safe, affordable places to live. Unfortunately, today more and more of our working-class residents who work in the heart of the city find it difficult to attain and keep affordable housing that keeps them close to their jobs.

Before we highlight some of the key figures outlining the contours of today's affordable housing crisis, we must first define the term affordable housing. There are two definitions, according to the US Department of Housing and Urban Development (HUD), for affordable housing-one for renters and one for homeowners. Affordable housing for renters is housing in which households spend less than $30 \%$ of their gross monthly income on housing costs, which includes rent and utility payments. For homeowners, affordable housing is defined as housing in which households spend less than $30 \%$ of their gross monthly income on mortgage, utility, property taxes, and insurance payments. Families who spend more than this $30 \%$ threshold are said to be cost-burdened, and families who spend more the 50\% of gross earnings are said to be severely cost-burdened. ${ }^{1}$ Families who are housing cost-burdened at any level struggle to meet other financial obligations that are part

\footnotetext{
${ }^{1}$ Understanding the concept of cost burden is critical to making the connection to building a resilient New Orleans because we have already learned from Hurricane Katrina that it is not enough that people are able to have a roof over their heads. Being able to make the rent, or make the mortgage, or make the electricity bill (if there is outright ownership) without being able to save and having money for transportation, medical expenses, and/or food do little to build up the essential resiliency needed by low- to moderate-income families. Cost-burdened families are exactly those families who are unable to do that because their incomes are too low, and their rental/mortgage payments are too high, and the region provides little recourse for this imbalance to shift in a way that enables these families to find relief in the future.
} 
of life, such as health insurance, food, and transportation, to name a few. In addition, cost-burdened families struggle to save funds for rainy day emergencies, such as the type of funds needed for hurricane evacuations or other emergency needs after a disaster when weekly paychecks disappear.

It is important to note that many advocates and policy experts in housing are familiar with and make use of this definition in the work they do to advance affordable housing policies. ${ }^{2}$ However, most people (and often elected officials not familiar with the housing universe), particularly if they hail from middle- to upperincome communities where potential affordable developments are targeted, perceive affordable housing as a proxy for substandard or slum housing. Discussed more fully below, work to advance affordable housing strategies in New Orleans has required giving considerable attention to this misunderstanding with resident leaders, as well as elected and appointed decision-makers, in order to ensure their support rather than their opposition when enlisting them to help advance housing affordability measures and policies.

New Orleans has changed dramatically from 2000 to 2015, experiencing substantial shifts in population, households, income, and housing principally from the catastrophic jolt of Katrina. Some of the significant changes are as follows: the population decreased by $28 \%$, and households decreased by $21 \%$, with the average size of households dropping slightly by $6 \%$ from 2.48 people per household in 2000 to 2.33 in 2013; the African American population has declined 34\% (112,315 African American residents) since 2000, principally after Katrina in 2005. In 2013, $60 \%$ of the city's population was African American, down from $67 \%$ before Katrina (GNOHA 2015). Additionally, the number of people living alone has increased by $6 \%$, and the number of non-family households has increased by $7 \%$; meanwhile, the city's poverty rate remains incredibly high at $28 \%$ compared to $15 \%$ nationally, an overall increase of $2 \%$ since 2000 (GNOHA 2015). Despite this increase in poverty, the proportion of high-income households increased dramatically in the city, while the proportion of very low-income households also rose slightly. Housing costs have risen dramatically for both renters and homeowners when compared between pre-Katrina and post-Katrina levels, with home values increasing 54\% and rents increasing $50 \%$, while homeownership rates have remained relatively unchanged, decreasing from $46 \%$ to $45 \%$, still well below the national average of over $60 \%$ (GNOHA 2015).

This post-Katrina housing picture of decline in many indicators combines poorly with employment statistics. The majority of jobs in New Orleans' key economic sectors, tourism and medicine, pay wages below the citywide area family median

\footnotetext{
${ }^{2}$ In addition to the affordable housing definition, HUD designates area median family income (AMFI) as the baseline family income measurement used for determining affordability for a given geographic unit. Using AMFI, HUD designates families as follows: earning 50\%-80\% of AMFI in a given geography as low-income (LI) families; earning below $50 \%$ of AMFI as very lowincome (VLI) families; and earning no more than 30\% of AMFI (or families who fall below the federal poverty level) as extremely low-income (ELI) families. Using HUD's affordable housing definition and its area median income categories, we can present a snapshot of the New Orleans housing crisis.
} 
income of $\$ 33,600$ (for one person household), and the housing affordability crisis starts to become apparent (GNOHA 2015). Low monthly incomes and high costs of living, including housing costs, put a strain on working New Orleanians' and their families' abilities to find and secure safe, affordable housing. Consider New Orleans' musicians, culture bearers, and tourism workers who are key to attracting tourism to the city and who do not earn wages that match the cost of living in New Orleans. According to Ramsey (2013), in 2012, New Orleans musicians reported earning an average of $\$ 17,800$ a year, but $39 \%$ of those surveyed reported making less than $\$ 10,000$ per year. The average income for musicians has not increased significantly since 2008 , while housing prices have steadily increased.

Similarly, 33,801 people work in the Accommodation and Food Services industry in New Orleans, and these housekeepers, bartenders, fast-food employees, and hotel desk clerks earn less than $\$ 23,000$ a year, on average (Committee on Financial Services 2015). For these workers, the most they can afford to pay monthly as renters or homeowners is $\$ 575$ (including utilities, taxes, and insurance). Housing prices, however, have skyrocketed between 2000 and 2015. In 2015, at the time of the GNOHA's first-ever housing plan, a one-bedroom, market-rate apartment priced at $\$ 767$ per month (2015), well beyond hospitality workers' ability to cover this cost without worrying if they'll have enough to cover other living expenses.

Based on the information analyzed in the HousingNOLA plan, GNOHA anticipates a need for 33,600 new or rehabbed housing units over the next 10 years, with the highest homeowner/buyer and renter demands among low- to moderate-income families (2015). ${ }^{3}$ This means that a family of two with a combined household income of $\$ 44,575$ can afford approximately a $\$ 125,000$ mortgage (assuming $\$ 0$ down and excellent credit). In the neighborhoods increasingly becoming desirable by either newcomer permanent residents, real estate flippers, or short-term rental operators, median sales prices were $\$ 131,000$ in 2018 , already beyond what the average New Orleans family can afford without experiencing financial strain (Williams 2018).

The result of these changes is an evolving New Orleans. Though the total population number still remains below pre-Katrina levels, New Orleans was one of the fastest-growing cities in America during the 10 years after the storm. It remains one of the most attractive cities for millennials (Larino 2017). Evidence shows that the growing population is not just the result of returning residents but also an influx of new residents (Larino 2017). The changing demographics contributing to high housing demand, particularly with regard to newcomer, higher-income residents, create additional challenges to housing affordability, often compounding preexisting housing inequities around the city. These changes contribute to a large portion of New Orleans families who increasingly find themselves unable to afford homes that were affordable before Katrina. Working-class families, in particular, who experience severe cost burdens, face the toughest challenges. When these families purchase or rent housing today, the bulk of their gross income is consumed by

\footnotetext{
${ }^{3}$ The highest homeownership demand is by families earning between $\$ 29,717$ and $\$ 44,575$ for two- and three-bedroom homes, and the highest renter demand is by families earning less than $\$ 11,143$ and more than $\$ 37,146$, for one- and two-bedroom units (GNOHA 2015).
} 
housing costs, making them so cost-burdened that there is little room left financially to build the essential resilience that can mean the difference between poor and successful recoveries.

Before Katrina, New Orleans was a relatively insular city, a city where many people were "from here," deeply rooted in their neighborhoods, traditions, history, and unique culture, with multiple generations living in the same neighborhoods. As the city continues to change, partly as a continued effect of Katrina-related rebuilding efforts, many long-time residents are concerned about the economic effects newcomers are having on the city — especially regarding housing affordability.

When analyzed through a racialization lens (Omi and Winant 1994; Mills 1997), we find that African American households in New Orleans disproportionately pay more of their income toward housing costs than other racial and/or ethnic groups (GNOHA 2015). African Americans also comprise the majority of workers highlighted in the low-paying industries discussed above, making them one of the most cost-burdened groups in the city. New Orleans is now almost evenly divided between homeowners (47\%) and renters (53\%), but renters disproportionately pay more of their income toward housing costs. ${ }^{4}$ Racialized inequities show up within this population, as well, in which more than $60 \%$ of renting African Americans are cost-burdened in New Orleans compared to just $45 \%$ of whites (GNOHA 2015). These differences along racial lines are not new. On the contrary, racialized housing inequities is a well-documented social problem that has been traced to social, governance, and economic policies orchestrated by white elites and government agencies throughout the twentieth century (Massey 1993, Anderson and Massey 2001; Gotham 2000). Unfortunately, recent and current policies and practices have continued to fail to adequately account for these historical realities, continuing to exacerbate low- to moderate-income African American communities' abilities to build the essential resilience needed to contribute to the possibility of an exception New Orleans recovery from the next disaster.

Elected and appointed officials have been purveyors of historically racialized housing inequalities, whether unwittingly or otherwise, throughout the past 12 years. Consider the federally funded $\$ 9$ billion homeowner assistance program, labeled "the Road Home" program, managed by the then-newly formed state agency, the Louisiana Recovery Authority, specifically for the purpose of helping residents rebuild their damaged homes. From its inception, the program had design flaws that disproportionately affected working-class African American New Orleanians. Those who have not returned are often from poorer or minority neighborhoods in New Orleans, and their lack of resources was compounded by such design flaws. For example, to determine the award amount for rebuilding damaged homes, the Road Home program used either the pre-storm market value of a home or the cost to repair it, whichever of the two was lower. Two houses with the same square

\footnotetext{
${ }^{4}$ In 2013, 58\% (46,433) of households spent more than one-third of their income toward housing costs, and $37 \%(29,271)$ paid more than half of their income toward housing costs. New Orleans ranks second in the nation for the percentage of renters paying more than half of their income on housing, as described in the HousingNOLA report.
} 
footage and the same damage, but in different neighborhoods-for example, one in Lakeview, an affluent area of the city, and one in Gentilly, a mixed-income area of more modest homes-would have received dramatically different Road Home awards. Since many black homeowners lived in neighborhoods with lower market values, this resulted in awards much less than the cost to repair their homes. Other program rules, such as a $30 \%$ penalty for lack of flood insurance, affected homeowners with more sporadic incomes who were more likely to let policies lapse when budgets tightened. Duplication of benefits rules also reduced Road Home awards; housing assistance from FEMA was used to reduce Road Home awards, even if rebuilding was not physically possible when the FEMA assistance was distributed. Failure to account for the racialized disparities in locations of properties and household incomes, for example, at state policy-making levels resulted in a racially biased program that required court-mandated changes (Fletcher 2011; Beam 2012; Gotham 2014a). ${ }^{5}$

Other challenges included the tremendous burden of documentation. Many homeowners and renters lost important documents during the floods caused by the levee breaches after Katrina. Compiling enough proof to satisfy program requirements was a challenge that caused delays throughout the process. Even for homeowners who received a (smaller than anticipated) grant and were able to perform the construction work themselves, additional costs prevented homes from being fully repaired. Working on a house a little bit at a time leaves many elements exposed, creating mold from humidity, or unexpected water leaks from rain. Copper theft, especially in neighborhoods with few residents, meant that some owners had to replumb their homes or buy one air conditioner after another. Commuting costs were high in the years immediately after the storm, with many residents staying in affordable rentals outside the New Orleans area and returning to the city on weekends to work on their homes (Sheehan 2015). The barriers to recovery were numerous and compounding.

With rising housing prices and stagnant wages, it is becoming evident that the New Orleans housing market is increasingly unable to provide a sufficient supply of quality, affordable units. Further exacerbating these disparities in New Orleans is the recent private real estate sector boom, which has ushered in a process of gentrification ${ }^{6}$ that has spread beyond the limited geographic borders of trendy neighborhoods. Affluent individuals and families, as well as real estate flippers and short-term rental investors, have been purchasing and rehabilitating housing in

\footnotetext{
${ }^{5}$ It is important to note here the state's role in contributing to and advancing racialized inequitable approvals of Road Home funds that further hindered low- to moderate-income African American families to recover. Important in this is the almost full decade of families of limited resources attempting to rebuild without the same support given to middle-class or more affluent families until the lawsuit wins but also the state's descaling practices by using private partners to administer the program (see Gotham 2014b).

${ }^{6}$ We rely on the predominant usage of the term, which incorporates the idea of lower-income population displacement through either built environment upgrading, economic upgrading, or social upgrading, or a combination of any of these, in a given neighborhood (see Lees et al. 2010; Smith and Williams 1986).
} 
traditionally working-class African American neighborhoods all around the city, such as Hollygrove, Leonidas, Gentilly, the Upper ninth Ward, Black Pearl, and segments of the seventh Ward, pushing housing prices to levels well beyond the reach of the working folks who are being forced to look for affordable housing further out from the metro center where they have historically lived and worked.

Cities facing similar dilemmas have explored several potential solutions, from attempts to increase income, increase housing supply, or increase subsidies for housing. This issue is even more critical for New Orleans, with an economy that depends heavily on tourism. New Orleans' working-class families simply have not experienced earnings growth capable of meeting growing housing costs. With no sign of wages dramatically increasing in the very near future, it is critical that New Orleans creates housing that is affordable for the workers who support the backbone of the New Orleans economy. Doing this, however, is no easy task, as the housing universe is a field in which numerous competing interests from civic, business, and government spheres, all operating often at cross-purposes between local and state levels, do not seem to fully grasp what a wicked problem is collectively faced.

\subsection{Building a Broad-Based Regime from the Ground Up}

In 2007, just 2 years after Katrina, a group of nonprofit community development leaders came together to strengthen their abilities to help each other during the early years of recovery and rebuilding efforts in New Orleans. Over time, this group coalesced into the Greater New Orleans Housing Alliance (GNOHA), an organization of housing advocates, developers, educators, and public office decisionmakers who collectively perceived a significant gap in housing affordability leadership and coordination in the City of New Orleans and the State of Louisiana. Andreanecia Morris, serving as lead organizer of the group, assumed a leadership role and in 2012 led the formal incorporation of the coalition into an advocacy and lobbying organization.

GNOHA's evolution (from monthly learning and information sharing gatherings in 2007 to monthly political influence and housing affordability policy discussions in 2012), rose out of a deepening understanding that the overly complex housing field, rife with competing power players, strong personalities, shifting political alliances, and fluctuating economic forces, needed a steady, mission-oriented ${ }^{7}$ leadership voice. However, desiring to have or build such a voice does not guarantee attainment of the power to influence anything. While we cannot say that today GNOHA is a representative example of the type of political regime required to advance a particular social justice agenda, we do believe that GNOHA can be

\footnotetext{
${ }^{7}$ The word mission used here is to be understood as an antithesis to a profit agenda. That is, mission-oriented work pursues the mission of the organized group (in our case, housing affordability for GNOHA) as its goal and not profit-making for a particular group or business.
} 
viewed as an example of how steps can be taken toward building such a regime. ${ }^{8}$ The following brief overview of GNOHA's work and ongoing challenges highlights the essential work required to build the type of political power needed to advance housing affordability strategies, especially after an extreme weather catastrophe such as Katrina posed.

\subsubsection{A Lesson from the Battle for Public Housing}

In 2007, the New Orleans City Council voted to allow the Housing Authority of New Orleans (HANO) to approve the demolition of "the Big Four," the four largest public housing developments in the city, to the displeasure and chagrin of an unhappy and boisterous crowd in attendance (Nossiter and Eaton 2007). Advocates who had looked to the City Council to stay the tide of a decades-long HUD initiative known as HOPE VI (mixed-income housing) felt betrayed by their locally elected officials, anticipating that the City Council would use its power to grant demolition permits to convince HANO to turn a ship around that had sailed some 10 years prior. The advocates' logic was simple: they wanted affordable housing immediately for the displaced low-income families of New Orleans who had yet to return by 2007, due to the severe shortages in housing stock in the years immediately after Katrina. Advocates relied on the moral high-ground demand to elected and appointed officials to "do the right thing," having little to no power as a collective group to influence any of the decision-makers.

Herein lies the key point that the remainder of this section highlights. Many advocates on the ground doing the work to bring affordable housing to their communities fail to appreciate the complexity of power brokers in a given urban setting, specifically how these power brokers interact and how market-oriented logics overwhelm socially oriented logics. At the time of the 2007 City Council decision to approve demolition of the "Big Four" public housing developments, GNOHA was little more than an initial set of welcoming meetings in which nonprofit housing developers, service providers, and advocates were getting to know each other and primarily reacted to experiences and changes in the field. While some members of the then-nascent group participated in activities designed to influence council members, GNOHA at that time was not in a position to participate meaningfully as an organized collective of organizations. The specter of the "Big Four" battle, however, may have provided the impetus to the group to begin to think in a more proactive manner.

\footnotetext{
${ }^{8}$ In applying regime politics theory, we recognize that GNOHA has initiated the process of building such a regime in New Orleans, but in its current iteration in 2018, this remains a work in progress that the organization hopes to achieve within the coming years. The expected outcome of building such a regime is more robust, sustainable policies that deeply engender housing affordability opportunities for low- to moderate-income families in the city.
} 


\subsubsection{The Start of Something Different}

In 2008, with nearly a full year of regular convenings and no clear direction yet as to which direction these gatherings would lead, participants of the meetings began to push for a strategic direction to the group. Some highlighted the potential power of a unified voice of housing professionals, pointing to how such a voice could help the efforts of the individual organizations assembled. Others pointed to the direct issues housing organizations were dealing with in helping residents navigate the Road Home program. Knowledgeable with first-hand experience, the group openly discussed its combined frustrations with the program's design and the lack of a strong enough voice to bring these issues to the attention of Road Home administrators at the State Capitol.

Conversations changed from reactive information sharing to participants asking for government officials to be invited to the meetings. This simple request may seem innocuous, but for advocate groups, this can be a highly polarizing line, with those in favor of including government officials pitted against those not in favor of such action, often on the grounds that members of government are not trustworthy partners. At the heart of this polarization lies a key philosophical position about how to effect social justice change as an advocate, stated simply as either working with government officials or working against them. Not everyone at the table was of the same opinion, but after some deliberation, the group agreed that it was worthwhile inviting government officials to meetings if only to educate the group on the most current thinking about housing policies and programs. With this agreement, GNOHA opened the door toward acceptance of, and ultimately adherence to, key foundational frameworks in its ongoing work to this day, research deeply, build broad relationships across the field, and work with government officials.

Between 2008 and 2009, GNOHA shifted its meetings from learning about participating members' organizational challenges to learning from government officials at different levels of governance about their housing work. The now better-organized group spoke to city, state, and federal officials across agencies, inviting them to speak at monthly meetings, ensuring ongoing learning and communication about housing policies and programs being considered and/or implemented. Through this initial effort, GNOHA began to build relationships with officials and learned about opportunities to provide input, give feedback, and present our ideas. The coalition members learned, for example, that there were consistent gaps in knowledge, with government officials lacking sufficient data and/or policy ideas that could help inform their work and local advocates and practitioners lacking clarity about decision-making parameters, timetables, and opportunities. During these learning opportunities, GNOHA leaders realized that if they could conduct the research, it could provide data-driven solutions to the same government officials with whom the members were beginning to build relationships.

The next step in development as a coalition evolved from this realization that the group could engage in policy analysis and recommendation, doing so in partnership with government officials, wherever possible. By the end of 2009, GNOHA evolved 
again, embarking on policy research, analysis, and writing, as well as agreeing to include government officials as members of the coalition (a decision that holds still in 2019). However, through 2015, GNOHA remained a small organization, despite having an average 40-50 annual member roster of organizations that included housing professional advocates, service providers, nonprofit developers, and government officials. ${ }^{9}$ Compared to the Industrial Areas Foundation (IAF) model of community organizing, which has more than eight decades of successful organizing across the United States, the group was certainly not broad in its membership (Chambers 2003).

\subsubsection{Toward a Broad-Based Regime ${ }^{10}$}

Before moving further, it is important to clarify what we mean by the phrase broadbased regime. Beginning with the word regime, we want to emphasize the theoretical understanding of this word, borrowed from and framed upon Stone's conceptualization $(1989,1998,2006)$, which refers to an organized coalition of power brokers across sectors in an urban setting who/that have agreed to pursue a shared vision through a set of programmatic and/or legislative policies. We cannot say that GNOHA and its sister organization HousingNOLA ${ }^{11}$ in 2019 constitute a regime in the housing field, but it is the direction in which the organizations are intentionally heading. Without meaningful participation across business, civic, and governance sectors at local and state levels in the intentional pursuit of affordable housing solutions, GNOHA will not have the requisite power to see ideas reach adoption and implementation. Building such a regime requires dialoguing, wherever possible (we note that sometimes it is not possible), across ideological lines, across political partisan lines, and certainly across advocate-government lines, in an effort to bridge understanding and build the needed unified voice that enables solutions that benefit cost-burdened families who are quickly running out of affordable housing options in New Orleans. We conceptualize a broad-based regime as involving not only the power brokers mentioned above but also the volunteer public involvement of everyday residents.

\footnotetext{
${ }^{9}$ In 2015, it had one full-time staff member and two fellows. The 2-year GNOHA Road Home Liaison Group contract with the State of Louisiana added three full-time contractors from 2015 to 2017. The volunteer Board of Governors oversees policy and advocacy efforts and the chair serves as president managing the day-to-day activities.

${ }^{10}$ The concept builds on the IAF idea of a broad base and the regime politics theory of a powerful political regime base by combining the two to incorporate four distinct groups: everyday residents, political decision-makers, business leaders, and professional nonprofit leaders. Everyday residents comprise all folks interested in being civically involved but who are not professional nonprofit staff.

${ }^{11}$ The HousingNOLA plan initiated by GNOHA also gave rise to the creation of a 501(c)3 organization that could focus on the civic involvement and education of everyday residents on housing issues. This new organization, created in 2015, is named HousingNOLA (sharing the title of the report also mentioned here).
} 
Through the years, GNOHA has had some successes in this building effort and, of course, many failures. One highly significant, if only temporary, recent success involves Governor John Bel Edwards and Louisiana Senate Bill 462. Louisiana Senate Bill 462, from the 2018 Legislative Session, targets municipalities attempting to create affordable housing units by legislating that such units be included in new, market-rate developments. This strategy is generally known as inclusionary zoning. The bill bans mandatory inclusionary zoning policies outright at the municipal level, effectively eradicating a municipality's ability to act locally in dealing with housing affordability issues (Louisiana Senate Bill 462). GNOHA members and HousingNOLA partners were aware of the bill and actively worked with other legislators, aides to Governor Edwards, and other channels to keep the bill from passing, as GNOHA deemed it severely harmful to its ability to promote one of the key strategic tools in the housing affordability toolbox. Thanks, in part (GNOHA members believe), to these efforts, Governor Edwards vetoed the bill, which had made it out of the Senate floor (Edwards 2018). However, this veto depends on a city making use of an inclusionary zoning policy before the 2019 Louisiana legislative session, with a stipulation that the governor would sign a similar bill in 2019 if it reached his desk and no city has shown a need for such a policy. While GNOHA rightly views the 2018 veto as a small win for affordable housing advocates, the governor's caveat serves as a reminder that the power to influence government officials that GNOHA's members have cultivated since 2008 remains limited in scope and reach. The work is far from done.

Of course, GNOHA members went to work locally, holding conversations with the Mayor of New Orleans, as well as New Orleans City Council officials, the City Planning Commission, and respective staff for each. Through this work, GNOHA recently experienced a partial victory when on November 13, 2018, New Orleans City Planning Commission approved a set of recommendations for zoning changes that included inclusionary zoning incentives for future multi-housing development (Evans 2018). As a follow-up to this approval, on January 24, 2019, the New Orleans City Council passed a motion to draft new ordinances. This vote rejected recommendations from the City Planning Commission that would have not included mandatory inclusionary zoning as the centerpiece of the Smart Housing Mix. While the new policy is being drafted, the Council requires data from an as-yet unfinished feasibility study that was being conducted at the time in order to determine the most viable option to consider next (Litten 2019). This brings New Orleans closer to a mandatory inclusionary zoning policy to the City of New Orleans, and if we are able to accomplish a city council vote before a similar bill to 2018's Senate Bill 462 passes through committee, house, and senate floors in 2019, then GNOHA will have accomplished a significant piece of its multi-pronged solutions recommendations (GNOHA 2015).

GNOHA's recommendation on inclusionary zoning comes directly out of our 2015 HousingNOLA plan, in which the coalition articulates a 10-year strategy and implementation plan for creating more affordable housing for New Orleans residents (GNOHA 2015). However, this plan could easily remain a shelf ornament were it not for the intentional work GNOHA began in 2012 to engage non-housing 
professionals in our efforts. Without a base that includes residents from all walks of life, GNOHA would simply be a coalition of housing professionals in the business, government, and civic sectors. While a feat in and of itself to bring these disparate professional groups together, GNOHA members agreed early on that inclusion of residents needed to be a priority, which began in earnest after incorporating as a 501 (c) 4 in 2012.

After agreeing to create a housing plan, GNOHA intentionally set out to build a broad base, hosting a housing summit in 2014, which served as the launching point for a set of community meetings held throughout the city, in which GNOHA members and residents codeveloped a housing plan. In 2017, GNOHA and HousingNOLA launched a multi-year campaign, titled Put Housing First, designed to secure 80,000 pledges over the next 10 years, and in 2018 implemented a housing affordability awareness march in order to bring attention of the issue to a broader audience. These efforts combined have the intention of informing and including residents who are not housing professionals in the effort to build a unified voice for housing affordability.

Today GNOHA continues to explore and expand ways of incorporating more residents, as the base can never be broad enough. Members of GNOHA are certain that had the group not intentionally included residents in this work, the type of actions taken by the New Orleans City Council in the last 3 months may not have occurred at all.

\subsubsection{Work on the Buy-In}

Ten years after convening with housing-oriented nonprofits, GNOHA has developed into a significant voice on issues of housing affordability. However, this work is far from over, and continues to present endless challenges. As mentioned above, GNOHA is moving toward building an affordable housing regime, but it is not there yet. One major reason for this is that the very term affordable housing fails to elicit a unified response. There are still many constituents, be they residents, government officials, or private developers, who scoff at the idea that New Orleans needs affordable housing, or who believe that affordable housing is a dirty word, or who simply fail to understand the basic concept that families cannot afford basic, decent, and safe housing because of external social forces. Not everyone, unfortunately, has bought in to this issue as requiring attention, despite a 2018 survey of mayors across the United States recognizing insufficient living-wage jobs and high housing costs as the top two obstacles to social mobility (Initiative on Cities 2019). We would add that, in our estimation, these are the top two obstacles to building essential resilience to disasters: housing cost burden and lack of living wages.

Building buy-in requires intentional work that targets not just housing advocates and providers, but also the general public, the business sector, government officials, and other non-housing advocates and service providers. As housing advocates, we have a clear definition for the term affordable housing that we believe everyone can 
understand, but it is not universally understood, much less accepted. In order to explore the types of solutions that can support cost-burdened families at local levels, affordable housing as a real issue needs to be better understood by cities so that discussions can incorporate the disconnects among cost-burdened families, low wages, and poor transportation, for example. GNOHA's efforts through the Put Housing First campaign, the march in 2018, and ongoing participation on local radio and television talk shows help promote this understanding in New Orleans, which we believe contributes to mitigating against traditional skepticisms.

\subsection{Recommendations}

The following set of recommendations for advancing housing affordability in cities is directly copied from the 2015 HousingNOLA Plan created by GNOHA, the Mayor's Office of Community Development and the Foundation for Louisiana. The plan can be downloaded directly from www.housingnola.org/main/plans. The recommendations fall under five priorities, which are as follows.

1. Preserve existing supply and expand the total supply of affordable rental and homeownership opportunities throughout your city. A recommended strategy includes creating a working partnership among city officials, other government officials, housing advocates, and housing providers to increase create/update housing stock, with time-limited targets in 5-year increments to evaluate and measure.

2. Prevent future displacement through development activities and continued study and policy review. A recommended strategy includes creating standard zoning polices and working with key stakeholders to develop workforce housing strategies and other creative ideas that assist cost-burdened families dealing with the pressures of higher costs brought about by gentrification. For example, in New Orleans, through work with the Assessor's Office, a referendum passed in the 2018 local elections to allow homeowners in gentrifying neighborhoods to ease into their increased taxes over time rather than immediately upon new assessments reflecting rapid neighborhood changes.

3. Enforce and promote fair housing policies throughout your city. This work, while not new in the affordable housing toolkit, remains underutilized. It requires comprehensive, coordinated work across sectors to improve fair housing practices in renting, selling, buying, safety, and so on. Rather than leaving this issue up to chance, cities are encouraged to actively and intentionally work with advocates and businesses to engage proactively.

4. Encourage sustainable design and infrastructure for all residents in your city. Working collaboratively with private, civic, and government leaders, study your city's market, and determine feasible incentives to consider for local or state legislative sessions. 
5. Increase accessibility for all, including residents with special needs in your city. Housing affordability is not an issue for just one group of people, as it affects individuals and families across all walks of life. Ensure that housing affordability policies intentionally include and align with other city policies aimed at addressing the issues faced by special needs population.

\subsection{Discussion}

This chapter provides a brief snapshot of the complexity behind understanding housing affordability factors (both historical and current), how these factors interact at the local New Orleans level, and how advocates, along with business and government leaders, can work together with residents to build regimes with enough power to implement policies that address affordable housing inequities. As such, we hope the chapter can inform future research into the roles and relationships of and among different players in local housing fields and how these interact and build regimes capable of implementing desired policies aimed at creating housing affordability. With mayors across the country recognizing the connection between wages and housing affordability as vital to the economic vitality of their residents, we hope more cross-disciplinary channels are explored by practitioners who advocate for affordable housing and living wages throughout the United States, particularly as it relates to considering housing affordability as a key strategy for building extreme weather essential resilience among cities' residents.

\subsection{Conclusion}

A true broad-based political regime that (1) is cognizant of how housing costburdens keep a significant portion of the population from building the required essential resilience to respond to disasters and (2) makes housing affordability for low- to moderate-income families its goals has the potential to counter the traditionally and historically market-oriented and racialized approaches to housing that has plagued most cities and enhanced its residents' vulnerabilities. We see a key policy opportunity not just for New Orleans, but also for other cities, to install policies that tackle the growing housing affordability crisis in such a way that it can enable the thousands and hundreds of thousands of working families in all cities to be able to afford a safe, decent home that does not cost-burden them in any fashion. Accomplishing such a feat would enable families to focus on building the essential resilience they need to deal with future disasters without such disasters becoming a catastrophic event for them and the cities in which they live. If housing affordability isn't intentionally addressed post disaster, Katrina has shown us that traditional market forces left unchecked will simply push vunerable working families to the fringes of society by exacerbating and even expanding socioeconomic inequalities, which in turn contribute in converting disasters for these families into catastrophes. 


\subsection{Postscript}

Our brief snapshot in this chapter provides a glimpse into the growing cost burden of working-class families in New Orleans, and within this group we want to specifically close with a brief mention of the impact gentrification is having on our culture bearers. Culture bearers include musicians, artists, Black Masking Indians, Social Aid and Pleasure Clubs, and a host of other creative individuals who contribute to the cultural experience packaged and sold around the world as being uniquely New Orleans. The majority of our culture bearers hail from working-class families who before Katrina lived in the same neighborhoods across the generations. Housing before the storm was deeply affordable, allowing culture bearers who earned less than $\$ 20,000$ a year to remain home and continue to keep New Orleans culture alive. With housing prices going up, these same families and individuals are increasingly finding it difficult to stay in the neighborhoods they historically called home, straining their abilities to continue to create the cultural texture so many tourists enjoy when they visit. If we are not successful at creating the affordable housing stock these folks need, we indeed run the risk of losing what is "New Orleans."

\section{References}

Anderson, E., \& Massey, D. S. (2001). Problem of the century: Racial stratification in the United States. New York: Russell Sage Foundation.

Beam, J. (2012, January 5). Attorneys big winners in Road Home lawsuit. The Hayride. Retrieved from https://thehayride.com/2012/01/attorneys-big-winners-in-road-home-lawsuit/

Campbell, M. (1998). Institutional ethnography and experience as data. Qualitative Sociology, 21(1), 55-73. https://doi.org/10.1023/A:1022171325924.

Chambers, E. T. (2003). Roots for radicals: Organizing for power, action, and justice. New York/ London: Continuum.

Committee on Financial Services. (2015). New Orleans: Ten years after the storm, Subcommittee on Housing and Insurance. Retrieved from https://www.govinfo.gov/content/pkg/CHRG114hhrg99779/html/CHRG-114hhrg99779.htm.

Edwards, J. B. (2018, May 26). Veto Senate Bill 462 letter [Louisiana Office of the Governor correspondence]. Retrieved from http://gov.louisiana.gov/assets/docs/BillsSigned/AlarioLtr2018-05-26-veto-SB-462.pdf

Evans, B. (2018, November 13). New Orleans steps closer to affordable housing requirement for developers. Nola.Com. Retrieved from https://www.nola.com/politics/2018/11/new-orleanssteps-closer-to-affordable-housing-requirement-for-developers.html

Fletcher, M. A. (2011, July 6). HUD to pay $\$ 62$ million to La. homeowners to settle Road Home lawsuit. Washington Post. Retrieved from https://www.washingtonpost.com/business/ economy/hud-to-pay-62-million-to-la-homeowners-to-settle-road-home-lawsuit/2011/07/06/ gIQAtsFN1H_story.html

Fligstein, N., \& McAdam, D. (2012). A theory of fields. New York: Oxford University Press.

Germany, K. B. (2007). The politics of poverty and history: Racial inequality and the long prelude to Katrina. Journal of American History, 94(3), 743-751. https://doi.org/10.2307/25095135.

GNOHA. (2015). HousingNOLA final report and ten year strategy and implementation plan for a more equitable New Orleans (housing analysis and recommendations). New Orleans: Greater New Orleans Housing Alliance. Retrieved from http://flux.modiphy.com/files/view/14208. 
Gotham, K. F. (2000). Racialization and the state: The Housing Act of 1934 and the creation of the Federal Housing Administration. Sociological Perspectives, 43(2), 291. https://doi. org $/ 10.2307 / 1389798$.

Gotham, K. F. (2014a). Reinforcing inequalities: The impact of the CDBG program on post Katrina rebuilding. Housing Policy Debate, 24(1), 192-212. https://doi.org/10.1080/105114 82.2013.840666.

Gotham, K. F. (2014b). Racialization and rescaling: Post-Katrina rebuilding and the Louisiana Road Home Program. International Journal of Urban and Regional Research, 38(3), 773-790.

Gotham, K. F. (2015). Limitations, legacies, and lessons: Post-Katrina rebuilding in retrospect and prospect. American Behavioral Scientist, 59(10), 1314-1326. https://doi. org/10.1177/0002764215591186.

Initiative on Cities. (2019). Menino survey of mayors (p. 38). Boston: Boston University. Retrieved from http://www.surveyofmayors.com/reports/Menino-Survey-of-Mayors-2018-FinalReport. pdf.

Larino, J. (2017, June 8). New Orleans is a top-growing city for millennials: Report. NOLA.Com. Retrieved from http://www.nola.com/business/index.ssf/2017/06/millennials_moving_new_ orleans.html

Laska, S. (2012). Dimensions of reality: Essential resiliency, exceptional recovery and scale. International Journal of Critical Infrastructures, 8(1), 47-62.

Lees, L., Slater, T., \& Wyle, E. (Eds.). (2010). The gentrification reader. New York: Routledge.

Litten, K. (2019, January 25). New Orleans steps carefully toward affordable housing requirements. Nola.Com. Retrieved from https://www.nola.com/politics/2019/01/on-affordable-housing-new-orleans-city-council-takes-early-steps-knowing-more-work-lies-ahead.html

Louisiana Senate Bill 462, Baton Rouge, Louisiana.

Massey, D. S. (1993). American apartheid: Segregation and the making of the underclass. Cambridge: Harvard University Press.

McNicoll, G. (1996). At risk: Natural hazards, people's vulnerability, and disasters. Population \& Development Review, 22(1), 169-170. https://doi.org/10.2307/2137699.

Mills, C. W. (1997). The racial contract. Ithaca: Cornell University Press.

Molotch, H. (1976). The city as a growth machine: Toward a political economy of place. American Journal of Sociology, 82(2), 309-332. https://doi.org/10.1086/226311.

Molotch, H., \& Logan, J. (1983). Tensions in the growth machine: Overcoming resistance to valuefree development. Social Problems, 31, 483-499. https://doi.org/10.2307/800236.

Nossiter, A., \& Eaton, L. (2007, December 21). New Orleans council votes for demolition of housing. The New York Times. Retrieved from https://www.nytimes.com/2007/12/21/us/ nationalspecial/21orleans.html

Omi, M., \& Winant, H. (1994). Racial formation in the United States: From the 1960s to the 1990s (2nd ed.). New York: Routledge.

Pensoneau-Conway, S. L., \& Toyosaki, S. (2011). Automethodology: Tracing a home for praxis oriented ethnography. International Journal of Qualitative Methods, 10(4), 378-399. https:// doi.org/10.1177/160940691101000406.

Pistrika, A. K., \& Jonkman, S. N. (2010). Damage to residential buildings due to flooding of New Orleans after Hurricane Katrina. Natural Hazards, 54(2), 413-434.

Ramsey, J. (2013, May 1). Sweet home: 2012 state of the New Orleans music community report. OffBeat Magazine. Retrieved from http://www.offbeat.com/news/sweet-home-neworleans-releases-2012-state-new-orleans-music-community-report/

Sheehan, M. A. (2015, October 1). Detours on the Road Home. Shelterforce. Retrieved from https://shelterforce.org/2015/10/01/detours_on_the_road_home/

Smith, N., \& Williams, P. (1986). Gentrification of the city. New York: Allen and Unwin.

Stone, C. N. (1989). Regime politics: Governing Atlanta, 1946-1988. Lawrence: University Press of Kansas.

Stone, C. N. (1998). Regime analysis and the study of urban politics, a rejoinder. Journal of Urban Affairs, 20(3), 249-260. https://doi.org/10.1111/j.1467-9906.1998.tb00421.x. 
Stone, C. N. (2006). Power, reform, and urban regime analysis. City \& Community, 5(1), 23-38. https://doi.org/10.1111/j.1540-6040.2006.00151.x.

Thompson, R. (2018, December 2). Despite rising prices, one segment of New Orleans' housing market has softened: \$1 million-plus homes. The Advocate. Retrieved from https://www.theadvocate.com/new_orleans/news/business/article_ef0ff0d6-e442-11e8-84d10fd4bb524a04.html

Tierney, K. J. (1999). Toward a critical sociology of risk. Sociological Forum, 14(2), 215-242. https://doi.org/10.1023/A:1021414628203.

Tierney, K. (2010). Growth machine politics and the social production of risk. Contemporary Sociology, 39(6), 660-663. https://doi.org/10.1177/0094306110386715b.

Williams, J. (2018, June 17). Growth in New Orleans home prices may force out longtime residents, study says. The Advocate. Retrieved from https://www.theadvocate.com/new_orleans/ news/article_9777cdb8-6e7b-11e8-b76a 575e44aca6f8.html

Open Access This chapter is licensed under the terms of the Creative Commons Attribution 4.0 International License (http://creativecommons.org/licenses/by/4.0/), which permits use, sharing, adaptation, distribution and reproduction in any medium or format, as long as you give appropriate credit to the original author(s) and the source, provide a link to the Creative Commons license and indicate if changes were made.

The images or other third party material in this chapter are included in the chapter's Creative Commons license, unless indicated otherwise in a credit line to the material. If material is not included in the chapter's Creative Commons license and your intended use is not permitted by statutory regulation or exceeds the permitted use, you will need to obtain permission directly from the copyright holder.

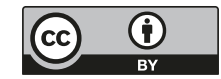

